\title{
Pemanfaatan Vinasse -Limbah Industri Alkohol- untuk Perbaikan Sifat Fisik Tanah dalam Pengembangan Tebu (Saccharum officinarum L) di Lahan Pasir Pantai
}

\author{
M. Zulfan Arrodli ${ }^{1}$, Muhartini' ${ }^{2}$, dan Taryono ${ }^{2}$ \\ ${ }^{1}$ Mahasiswa S1 Agronomi Fakultas Pertanian UGM \\ ${ }^{2}$ Pengajar Fakultas Pertanian UGM \\ email: taryono@faperta.ugm.ac.id
}

\begin{abstract}
Abstrak
Lahan pasir pantai merupakan lahan bermasalah untuk pertanian karena sifat tanahnya tidak mendukung pertumbuhan tanaman dan vinasse merupakan limbah industri ethanol yang jumlahnya sangat besar yang apabila dibuang di lahan terbuka akan mencemari lingkungan. Penggunaan vinasse sebagai bahan perbaikan tanah tanpa memberikan pengaruh negatif kemungkinan dapat dikerjakan untuk tanah bertekstur kasar seperti tanah di lahan pasir pantai. Oleh karena itu dalam penelitian ini, vinasse akan dicoba digunakan untuk membudidayakan tebu pada media tanah yang diambil dari lahan pasir pantai. Penelitian menggunakan pendekatan percobaan pot faktorial $4 \times 4$ yang disusun dalam rancangan lingkungan acak lengkap dengan 3 ulangan. Hasil penelitian menunjukkan bahwa pemberian vinasse dengan dosis 60.000 l/ha hanya sekali pada awal penanaman tebu mampu memperbaiki kemampuan tanah menyimpan air. Vinasse terbukti tidak memberikan pengaruh kurang baik terhadap tanaman yang dibudidayakan, bahkan pemberian vinasse cenderung memperbaiki pertumbuhan tebu baik dilihat pada tinggi tanaman, diameter batang, berat kering akar dan tajuk, meskipun pengaruhnya tidak berbeda nyata.
\end{abstract}

Kata kunci: Lahan pasir pantai, vinasse, tebu

\section{Pendahuluan}

Gula merupakan salah satu komoditas pertanian yang telah ditetapkan Indonesia sebagai komoditas khusus (special products) dalam forum perundingan Organisasi Perdagangan Dunia (WTO), bersama beras, jagung dan kedelai (Arifin, bobot tebu per hektar dan peningkatan rendemen (Anonim, 2008a). Perluasan areal dapat dilakukan dengan memanfaatkan lahan-lahan bermasalah yang salah satunya adalah lahan pasir pantai. Lahan pasir pantai mempunyai beberapa kelemahan apabila akan digunakan dalam budidaya pertanian diantaranya bertekstur kasar, daya simpan air dan hara rendah, kemampuan menukar kation rendah, daya meloloskan air dan udara tinggi, kandungan bahan organik rendah dan mudah tererosi (Kertonegoro et al., 2009). Untuk mengatasi keterbatasan lahan pasir pantai untuk budidaya pertanian maka harus diberikan masukan berupa bahan organik yang dapat diperoleh dari limbah agroindustri (Tejada et al., 2007). Salah satu limbah agroindustri yang kemungkinan dapat dimanfaatkan sebagi bahan organik adalah vinasse, slop, spentwash, potale, stillage vinasse, detritus dan dunder (Bhukya, 2007). Vinasse merupakan limbah cair berwarna gelap yang mengandung banyak bahan organik, hara nitrogen dan kalium yang dihasilkan dari proses fermentasi molase menjadi ethanol (Madejon et al., 2001). Pembuangan vinasse langsung ke alam bebas dapat menyebabkan pencemaran lingkungan, air dan tanah (Chidankumar 
et al., 2008). Penggunaan vinasse pekat langsung dilaporkan menghasilkan pengaruh yang kurang baik pada sifat tanah (Tejada et al., 2007), sedangkan pemberian vinasse yang diencerkan atau dikomposkan terlebih dahulu dapat memperbaiki sifat tanah (Kaushik et al., 2005) dan pertumbuhan tanaman (Chandraju et al., 2010). Meskipun penggunaan vinasse langsung untuk budidaya pertanian tidak disarankan, dalam penelitian ini vinasse akan digunakan untuk memperbaiki sifat fisik tanah pasir dan selanjutnya mengkaji pengaruhnya terhadap pertumbuhan tebu dengan harapan di kemudian hari tebu dapat ditanam di lahan pasir pantai melalui penggunaan vinasse.

\section{Metode Penelitian}

Bahan yang digunakan adalah empat klon tebu yang berasal dari PT. Madubaru, Madukismo, Yogyakarta; tanah pasir pantai yang diambil dari gumuk pasir di Pantai Parangtritis; SP 26; limbah cair Vinasse pabrik spiritus PT. Madubaru. Penelitian menggunakan pendekatan percobaan pot dengan rancangan perlakuan faktorial 4 x 4 yang disusun dalam Rancangan Acak Lengkap dengan 3 ulangan. Faktor pertama adalah 4 klon tebu yaitu klon PSJT 941, klon PS 865, klon PS 881, klon BL, sedangkan faktor kedua adalah dosis vinasse yaitu 0 (kontrol tanpa perlakuan), 20.000, 40.000, 60.000 l/ha. Pengamatan perubahan sifat fisik tanah meliputi berat volume tanah, berat jenis tanah, porositas total tanah dan kadar lengas tanah, sedangkan pengaruhnya terhadap tanaman tebu dikaji melalui tinggi tanaman, diameter batang, panjang akar, volume akar, bobot kering akar dan bobot kering tajuk. Pengamatan dilakukan 4 bulan setelah perlakuan dan data dianalisis dengan pendekatan analisis keragaman serta apabila terdapat bedanya nyata antar perlakuan maka dilanjutkan pengujian rerata menggunakan uji jarak Duncan dengan tingkat kepercayaan 5\%.

\section{Hasil Penelitian dan Pembahasan}

Vinasse sebagai limbah industri pertanian berbentuk cair yang memiliki BOD (biological oxygen demand) dan COD (chemical oxygen demand) tinggi yang sering berbau tidak sedap, sehingga pembuangannya di alam terbuka akan menyebabkan pencemaran lingkungan, air dan tanah diketahui banyak mengandung bahan organik. Oleh karena itu, vinasse kemungkinan dapat digunakan untuk memperbaiki sifat tanah lahan pasir pantai. Untuk melihat penggunaan vinasse dalam perbaikan sifat tanah lahan pasir pantai dilaksanakanlah percobaan pot dan selang 4 bulan sekali pemberian dikaji pengaruh pemberian tersebut terhadap sifat fisik tanah dan pertumbuhan tanaman tebu. 


\section{Pengaruh Pemberian Vinasse Terhadap Sifat Fisik Tanah Pasir Pantai}

Tejada et al. (2007) melaporkan bahwa pemberian vinasse segar dapat memberikan pengaruh kurang baik pada sifat fisik, kimia dan biologi tanah, kemungkinan karena vinasse mengandung banyak kation dan asam fulvat yang dapat menyebabkan perubahan struktur tanah, sedangkan disini ditunjukkan bahwa pemberian vinasse satu kali sampai 60.000 l/ha tidak mempengaruhi berat volume, berat jenis dan porositas tanah (Tabel 1). Pemberian 60.000 l/ha vinasse bahkan memperbaiki kemampuan tanah dalam menyimpan air yang ditunjukkan dengan kadar lengas tanah yang nyata lebih tinggi dibandingkan pemberian vinasse hingga dosis 40.000 l/ha.

Tabel 1. Pengaruh Pemberian Vinasse terhadap beberapa sifat fisik tanah

\begin{tabular}{|c|c|c|c|c|}
\hline $\begin{array}{c}\text { Vinasse } \\
(1000 \mathrm{l} / \mathrm{ha})\end{array}$ & $\begin{array}{c}\text { Berat Volume } \\
\left(\mathrm{g} / \mathrm{cm}^{3}\right)\end{array}$ & $\begin{array}{c}\text { Berat Jenis } \\
\left(\mathrm{g} / \mathrm{cm}^{3}\right)\end{array}$ & $\begin{array}{c}\text { Porositas Total } \\
(\%)\end{array}$ & $\begin{array}{c}\text { Kadar Lengas } \\
(\%)\end{array}$ \\
\hline 0 & $1,51 \mathrm{a}$ & $3,10 \mathrm{a}$ & $51,19 \mathrm{a}$ & $3,65 \mathrm{~b}$ \\
\hline 20 & $1,54 \mathrm{a}$ & $3,08 \mathrm{a}$ & $50,06 \mathrm{a}$ & $4,01 \mathrm{~b}$ \\
\hline 40 & $1,51 \mathrm{a}$ & $3,06 \mathrm{a}$ & $50,61 \mathrm{a}$ & $3,82 \mathrm{~b}$ \\
\hline 60 & $1,39 \mathrm{a}$ & $3,00 \mathrm{a}$ & $51,31 \mathrm{a}$ & $5,02 \mathrm{a}$ \\
\hline CV $(\%)$ & 4,20 & 3,57 & 5,35 & 9,89 \\
\hline
\end{tabular}

Keterangan:

1. Kadar lengas tanah diukur pada tegangan $(p F)=4.2$

2. CV: Coefficient of Variation (nilai keragaman data)

3. Angka pada kolom yang diikuti huruf yang sama menunjukkan tidak berbeda nyata berdasarkan uji jarak Duncan dengan tingkat signifikansi 5\%.

Hasil ini menunjukkan bahwa vinasse mampu meningkatkan jumlah pori meso (menengah) dan menurunnya pori makro, sehingga daya menahan air meningkat, dan berdampak pada meningkatnya ketersediaan air untuk pertumbuhan tanaman. Hasil ini sesuai dengan laporan Ranzani (1956) cit. Matibiri (1996) yang menyatakan bahwa pemberian vinasse mampu meningkatkan water holding capacity (kapasitas menahan air). Dengan peningkatan kapasitas menahan air, paling tidak untuk sementara pemberian 60.000 l/ha vinasse mampu memperbaiki salah satu kelemahan sifat fisik tanah pasir yaitu kemampuan menahan air yang rendah. Dengan perbaikan sifat tersebut, paling tidak memberi harapan positif terhadap kemungkinan penggunaan lahan pasir pantai untuk pertanian yaitu menghindari terjadinya cekaman kekurangan air.

\section{Pengaruh Pemberian Vinasse Terhadap Pertumbuhan Tebu}

Hasil analisis keragaman terhadap tinggi tanaman, diameter batang, panjang dan volume akar, bobot kering akar serta tajuk tidak menunjukkan adanya interaksi antara faktor klon dengan dosis vinasse. Tinggi tanaman dan diameter batang hanya dipengaruhi oleh perbedaan klon tebu dan tidak dipengaruhi oleh dosis vinasse (Tabel 2). Klon PSJT 941 menampakkan pertumbuhan terbaik dibandingkan ketiga klon yang lain meskipun PSJT 941 tidak berbeda nyata dengan PS 881. 
Terdapat tanda bahwa perbaikan kemampuan tanah menahan air mampu memperbaiki tinggi tanaman, meskipun peningkatan tersebut tidak bermakna dibandingkan kontrol hingga pemberian 40.000 l/ha vinasse. Hubungan antara peningkatan lengas tanah dengan tinggi tanaman juga dipublikasikan oleh Kramer \& Kozlowski, 1979).

Peranan akar dalam pertumbuhan tanaman sama pentingnya dengan tajuk. Akar berfungsi menyediakan unsure hara dan air yang diperlukan dalam metabolism tanaman. Panjang, volume dan bobot kering akar tidak dipengaruhi baik oleh klon tebu dan dosis vinasse. Terdapat kecenderungan bahwa klon PS881 mempunyai total panjang akar yang lebih baik meskipun tidak berbeda dengan tiga klon yang lain. Pemberian vinasse cenderung mendukung pertumbuhan memanjang akar yang kemungkinan juga mampu meningkatkan pertumbuhan tajuk. Akar berfungsi sebagai organ yang bertanggung jawab agar tanaman dapat berdiri tegak, organ yang menyerap hara dan air serta melakukan berbagai aktivitas metabolisme dan membentuk berbagai persenyawaan yang diperlukan tanaman (Kramer \& Koslowski, 1979). Walaupun tanaman dapat menyerap hara dan air melalui daun, tetapi dibandingkan dengan jumlah yang diserap melalui akar, penyerapan melalui daun dapat diabaikan.

Tabel 2. Pengaruh pemberian vinasse terhadap beberapa komponen pertumbuhan tebu pada umur 120 hari setelah penanaman

\begin{tabular}{|l|c|c|c|c|c|c|}
\hline Perlakuan & $\begin{array}{c}\text { Tinggi } \\
\text { tanaman } \\
(\mathrm{cm})\end{array}$ & $\begin{array}{c}\text { Diameter } \\
\text { batang } \\
(\mathrm{cm})\end{array}$ & $\begin{array}{c}\text { Panjang } \\
\text { akar }(\mathrm{cm})\end{array}$ & $\begin{array}{c}\text { Volume } \\
\text { akar }(\mathrm{ml})\end{array}$ & $\begin{array}{c}\text { Bobot } \\
\text { kering akar } \\
(\mathrm{g})\end{array}$ & $\begin{array}{c}\text { Bobot } \\
\text { kering } \\
\text { tajuk }(\mathrm{g})\end{array}$ \\
\hline Klon tebu & & & & & & \\
\hline PSJT 941 & $249,45 \mathrm{a}$ & $1,97 \mathrm{q}$ & $1683,59 \mathrm{p}$ & $436,46 \mathrm{p}$ & $94,04 \mathrm{p}$ & $208,34 \mathrm{p}$ \\
\hline PS 865 & $225,36 \mathrm{~b}$ & $2,01 \mathrm{q}$ & $1552,60 \mathrm{p}$ & $329,38 \mathrm{p}$ & $72,08 \mathrm{p}$ & $201,54 \mathrm{p}$ \\
\hline PS 881 & $235,66 \mathrm{ab}$ & $2,19 \mathrm{p}$ & $1974,20 \mathrm{p}$ & $399,33 \mathrm{p}$ & $100,20 \mathrm{p}$ & $175,22 \mathrm{p}$ \\
\hline BL & $227,43 \mathrm{~b}$ & $1,94 \mathrm{q}$ & $1633,67 \mathrm{p}$ & $374,38 \mathrm{p}$ & $88,61 \mathrm{p}$ & $224,36 \mathrm{p}$ \\
\hline $\begin{array}{l}\text { Dosis vinasse } \\
(1000 \text { l/ha })\end{array}$ & & & & & & \\
\hline 0 & $233,42 \mathrm{p}$ & $2,02 \mathrm{a}$ & $1458,84 \mathrm{a}$ & $387,50 \mathrm{a}$ & $80,49 \mathrm{a}$ & $180,64 \mathrm{a}$ \\
\hline 20 & $231,50 \mathrm{p}$ & $2,03 \mathrm{a}$ & $1593,06 \mathrm{a}$ & $350,58 \mathrm{a}$ & $85,11 \mathrm{a}$ & $196,96 \mathrm{a}$ \\
\hline 40 & $233,60 \mathrm{p}$ & $2,04 \mathrm{a}$ & $2110,60 \mathrm{a}$ & $422,71 \mathrm{a}$ & $100,85 \mathrm{a}$ & $215,48 \mathrm{a}$ \\
\hline 60 & $239,37 \mathrm{p}$ & $2,01 \mathrm{a}$ & $1681,55 \mathrm{a}$ & $378,75 \mathrm{a}$ & $88,47 \mathrm{a}$ & $216,39 \mathrm{a}$ \\
\hline Interaksi & $(-)$ & $(-)$ & $(-)$ & $(-)$ & $(-)$ & $(-)$ \\
\hline CV $(\%)$ & 7,97 & 6,31 & 5,59 & 4,98 & 28,87 & 24,81 \\
\hline
\end{tabular}

Keterangan:

1. CV: Coefficient of variation (nilai keragaman data)

2. Angka pada kolom faktor klon dan dosis vinasse yang diikuti huruf yang sama menunjukkan tidak beda nyata berdasarkan uji jarak Duncan dengan tingkat signifikansi 5\%.

3. Tanda (-) menunjukkan tidak ada interaksi antara faktor klon dan dosis vinasse.

Pengaruh vinasse cenderung tidak linier, karena panjang dan volume akar pada pemberian 40.000 1/ha vinasse lebih tinggi meskipun tidak berbeda nyata dengan dosis yang lain. Dengan turunnya panjang akar dan volume akar pada pemberian 60.000 l/ha vinasse, kemungkinan disebabkan oleh 
pengaruh negatif dari pemberian vinasse segar seperti yang dicurigai oleh Tejada dan Gonzalez (2005) yang memberitahukan bahwa pemberian limbah pertanian kemungkinan akan menyebabkan pengaruh kurang baik terhadap penyerapan hara, pertumbuhan dan perkembangan tanaman serta kualitas hasil pertanian yang dihasilkan. Dengan perbaikan kandungan lengas tanah dan kemungkinan perbaikan kandungan hara tanah kemungkinan justru tidak memacu pertumbuhan akar, karena pertumbuhan akar telah banyak digunakan sebagai penciri tanaman tanah kering dan kekurangan hara. Pada kondisi tercekam kekurangan air dan hara, akar cenderung tumbuh lebih cepat memanjang.

Nampaknya alasan kedua yaitu ketersediaan lengas tanah yang lebih baik mempengaruhi pertumbuhan akar lebih dapat diterima. Meskipun pada pemberian 40.000 l/ha vinasse kemungkinan menghasilkan pertumbuhan akar yang lebih baik, yang juga ditunjukkan oleh bobot keringnya, tetapi pada akhirnya tetap menunjukkan bobot kering akar yang tidak berbeda nyata dengan perlakuan vinasse yang lain. Nilai bobot kering akar yang dihasilkan dengan pemberian $60.000 \mathrm{l} / \mathrm{ha}$ vinasse mendekati nilai bobot kering akar dengan pemberian $40.000 \mathrm{l} / \mathrm{ha}$ vinasse. Hal ini menggambarkan bahwa kualitas akar yang dihasilkan pada 60.000 l/ha vinasse sama baik dibandingkan dengan perlakuan yang lain. Kualitas akar pada pemberian 60.000 l/ha vinasse kemungkinan lebih baik dari tanah pasir yang tidak diperlakukan dengan vinasse.

Bobot kering tajuk seringkali digunakan untuk mengukur kemampuan tanaman membentuk biomasa yang dipengaruhi proses fotosinthesis dan respirasi. Bobot kering tajuk tidak dipengaruhi baik oleh klon maupun vinasse. Secara umum dapat dikatakan bahwa tebu yang ditanam pada tanah pasir yang diberi perlakuan vinasse cenderung memiliki bobot kering tajuk tebu yang lebih baik dibandingkan tebu tanpa penambahan vinasse, meskipun perbedaannya tidak nyata. Vinasse pada dosis tertentu selain mampu meningkatkan kemampuan tanah dalam menyimpan air, kemungkinan sekaligus juga memberikan tambahan unsur hara makro dan mikro bagi tanaman (Bustamante et al., 2005).

Dengan demikian dapat dikatakan bahwa penggunaan vinasse segar yang akan memberikan pengaruh kurang baik terhadap sifat fisik tanah dan mungkin pertumbuhan tanaman dalam penelitian ini tidak mampu dibuktikan. Terdapat beberapa alasan untuk menjelaskan hasil tersebut. Barzegar et al. (2002) menjelaskan bahwa pengaruh pemberain bahan organik terhadap sifat fisik tanah tergantung jumlah, macam dan ukuran dari bahan organik yang ditambahkan, sedangkan Armengol et al. (2003) dan Chandaju et al. (2010) menyimpulkan bahwa pengenceran dan pengomposan vinase dapat memperkecil pengaruh kurang baik dari vinasse. Vinasse limbah pabrik spiritus PT Madubaru, Madukismo, Yogyakarta mengandung 89,54 \% air dan 6.33\% gula total serta 
1,69\% bahan mengendap (Anonim, 2008b). Sifat ini kemungkinan yang memberikan pengaruh cukup menjanjikan dari vinasse libah spriritus PT Madubaru tanpa harus diencerkan bahkan dikomposkan terlebih dahulu. Untuk mengkaji penggunaan vinasse dalam budidaya pertanian, nampaknya perlu selalu dilakukan kajian kualitas vinasse yang akan digunakan.

\section{Kesimpulan}

Dari kajian awal tentang penggunaan vinasse limbah pabrik spiritus PT Madubaru ini sementara dapat disimpulkan:

1. Pemberian vinasse nyata mampu meningkatkan kadar lengas tanah khususnya pada pemberian dosis tinggi di atas $60.000 \mathrm{l} / \mathrm{ha}$

2. Pemberian vinasse tidak mempengaruhi pertumbuhan akhir tebu hingga umur 4 bulan setelah penanaman yang tergambarkan dari tinggi tanaman, diameter batang, panjang dan volume akar serta bobot kering akar dan tajuk.

\section{Ucapan Terima Kasih}

Dalam kesempatan yang baik ini penulis mengucapkan banyak terima kasih kepada Direktur PT Madubaru, Madukismo, Yogyakarta yang dengan sukarela telah mendukung kegiatan ini baik melalui pemberian vinasse maupun klon tebu. Penghargaan yang sangat besar diberikan kepada mahasiwa kelompok peneliti tebu Jurusan Budidaya Pertanian, Universitas Gadjah Mada yang tidak dapat disebutkan satu per satu yang telah bersusah payah agar supaya penelitian ini berhasil.

\section{Daftar Pustaka}

Anonim. (2008a). Konsep Peningkatan Rendeman Tebu untuk Mendukung Proses Akselerasi Industri Gula Nasional. http://p3gi.net/images/opini/ Konsep\%20Peningkatan\%Rendemen.pdf. diakses tanggal 29 Agustus 2009.

Anonim. (2008b). Analisis kimia limbah industri alkohol. Jurusan Kimia, Fakultas Matematika dan Ilmu Pengetahuan Alam, Universitas Gadjah Mada. Yogyakarta.

Arifin, B. (2008). Ekonomi swasembada gula indonesia. Economic Review, 211: 1-12.

Armengol, J. E., R. Lorenzo, N. Fernandez. (2003). Use of vinasse dilutions in water as an alternative for improving chemical properties of sugarcane planted vertisol. Cultivos Tropicales, 24: 73-76.

Barzegar, A. R., A. Yousefi, A. Daryashenas. (2002). The effect of addition of different amount and types of organic materials on soil physical properties and yield of wheat. Plant and Soil, 247: 295-301. 
Bhukya, T. D. (2007). Response of Maize (Zea mays L.) to Ferti-irrigation of Spentwash. Department of Soil Science and Agricultural Chemistry College of Agriculture. Dharwad University of Agricultural Sciences. Dharwad. India.

Bustamante M.A., C. Poredes, R. Moral, J. Moreno-Casseles, M. D. Perez-Murcia. (2005). Use of winery and distillery effluents in agriculture: characterization of nutrient and hazardous component. Water Science and Technology, 51: 145-151.

Chandraju S., C.S. Chidankumar, R. Venkatachalapathy. (2010). Irrigationan impact of distillery spentwash on growth, yield and nutrient of leafy vegetables. Bioresearch bulletin, 2: 83-90.

Chidankumar, C.S., S. Chandraju. (2008). Impact of irrigation of distillery spentwash on the nutrient of pulses in untreated and treated soil. Sugar Technology, 10: 314-318.

Kaushik, K., R. Nisha, K. Jogjaeeta, C. P. Kaushik. (2005). Impact of long and short term irrigation of a sodic soil with distillery effluent in combination with bio-amendments. Bioresource Technology, 96: 1860-1866.

Kertonegoro, B. A., D, Siddiq, Sulakhudin, A. Dairah. (2009). Optimalisasi Lahan Pasir Pantai Bugel. http://tanahdanlingkungan.blogspot.com/ 2009/05/optimalisasi -lahan-pasir-pantaibugel.html. diakses 16 Maret 2010.

Kramer P.J., T. T. Kozlowski. (1979). Physiology of Woody Plants. Academic Press New York. The USA.

Madejon, E., R. Lopez, J. M. Marillo, F. Cabrera. (2001). Agricultural use of three (sugar beet) vinasse compost: effect on crops and chemical properties of cambisol soil in the Guadalquivir river valey (South West Spain). Agriculture, Ecosystem, Environment, 84: 55-65.

Matibiri, B. (1996). The effects of stillage (Vinasse) on nine ratoon crops of Nco376 receiving full irrigation in the South-East Lowveld of Zimbabwe. Proceedings of South African Sugar Technology Association, 70: 63-66.

Tejada, M., J. L. Gonzalez. (2005). Beet vinasse applied to wheat under dryland conditions affect soil properties and yield. Eurepean Journal of Agronomy, 23: 336-347.

Tejada, M., J. L. Moreno, M. T. Hernandez, G. Garcia. (2007). Application of two beet vinasse in soil restoration effects on soil properties in an arid environment in Southern Spain. Agriculture, Ecosystem and Environment, 119: 289-298. 